\title{
The Relationship Between Mothers' Affective Parenting and Preschoolers' Peer Competence : Mediating Effects of Preschoolers' Executive Function and Emotion Regulation
}

\author{
Ran Hee Yoo, Sun Hee Kim \\ Department of Child Development \& Family Studies, Busan, Korea \\ 어머니의 애정적 양육행동과 유아의 또래유능성과의 관계 \\ : 유아의 실행기능과 정서조절의 매개효과 \\ 유란희, 김선희 \\ 부산대학교 아동가족학과
}

\begin{abstract}
Objective: The purpose of this study was to explore the mediating effects of executive function and emotion regulation of preschoolers on the relationships between mothers' affective parenting and preschoolers' peer competence.

Methods: The participants were 3 to 5 year old preschoolers and their mothers $(N=241)$ living in Busan and Kyungnam province. Data analysis methods included descriptive statistics, Cronbach $\alpha$, Pearson's correlation analysis, and SEM. Data were analyzed using the SPSS Statistics 23.0 program and Amos 23.0 program.

Results: The major findings of this study are as follows. First, mothers' affective parenting, preschoolers' executive function, emotion regulation, and peer competence correlated positively. Second, the relationship between mothers' affective parenting and preschoolers' peer competence was mediated by preschoolers' executive function and emotion regulation.

Conclusion: These findings suggest the importance of mediating effects of preschoolers' executive function and emotion regulation on the relationship between mothers' affective parenting and preschoolers' peer competence.
\end{abstract}

Keywords: affective parenting, executive function, emotion regulation, peer competence

\begin{abstract}
서론
여성의 사회 경제 활동의 증가, 가족 규모의 축소, 그리고 보 육료 지원 정책 등은 유아들의 보육기관 이용 시기를 앞당기 고 있다. 이로 인해 유아들이 또래들과 보내는 시간이 증가하 게 되면서 유아기 발달에 있어 또래집단의 중요성이 더욱 부

Corresponding Author: Sun Hee Kim, Department of Child Development \& Family Studies, Pusan National University, 2, Busandaehak-ro 63beongil, Geumjeong-gu, Busan, Korea

E-mail: kremedy@pusan.ac.kr
\end{abstract}

각되고 있다. 유아기는 기본적인 사회화 과정이 시작되는 시 기로서 이 시기 또래는 사회화의 중요한 대리인으로서 유아의 발달에 기여하는데(Shaffer, 2005), 유아들은 또래들과의 상호 작용 경험을 통해 사회적인 기술을 습득하거나 습득된 기술을 연습할 기회를 갖게 된다. 유아기 동안의 또래와의 긍정적인 관계 형성과 적절한 사회적 기술 습득은 아동기 이후의 긍정

(c)The Korean Association of Child Studies

This is an Open Access article distributed under the terms of the Creative Commons Attribution Non-Commercial License (http:// creativecommons.org/licenses/by-nc/4.0) which permits unrestricted noncommercial use, distribution, and reproduction in any medium, provided the original work is properly cited. 
적 발달을 예측할 수 있다(Jung \& Chi, 2006; Rubin, Bukowski, $\&$ Parker, 2006).

일반적으로 또래관계에서의 사회적 유능감을 의미하는 또 래유능성은 또래와의 관계를 효과적으로 형성 및 유지하고, 적합한 방식으로 또래관계 내 자신의 목표를 달성하는 능력 (Park \& Rhee, 2001)을 의미한다. 또래유능성이 높은 유아는 친구들과 잘 어울리며 친사회적이고 능동적으로 활동에 참여 하며 주도적인 특성을 가진다. 따라서 가정을 벗어나 보육기 관에서 보내는 시간이 증가하고 또래와의 상호작용이 빈번해 지는 유아기에 있어 또래유능성은 중요한 발달과업 중의 하나 라고 할 수 있다.

유아의 또래유능성 발달에 있어 어머니의 양육행동은 일차 적으로 중요한 역할을 한다. 일반적으로 어머니의 애정과 관 심을 받으며 성장한 유아는 또래와의 관계에서도 유능한 사 회적 능력을 보이는(Chae, 2010) 반면, 어머니가 자녀를 애정 적으로 수용하지 못할수록 유아는 자신감이 결여되어 활동에 잘 참여하지 않거나 또래 아이들과 원활하게 상호작용하며 지 내는 데에 어려움을 보일 수 있다(Moon, 2007). 어머니의 양육 행동이 유아의 또래유능성에 미치는 영향을 규명한 몇몇 연 구들(Choi, 2014; H.-N. Kim \& Lee, 2008; J. H. Lee \& Moon, 2008; Y. Lim, 2002)은 수용적이고 온정적이며 자녀에게 관심 과 애정을 갖고 표현하는 애정적 양육행동(Rohner, Khaleque, $\&$ Cournoyer, 2005)이 또래유능성에 긍정적인 영향을 미치는 (Choi, 2014; J. H. Lee \& Moon, 2008) 반면 거부적이고 통제적 인 양육행동은 또래유능성과 유의한 관련성이 없거나(Choi, 2014; J. H. Lee \& Moon, 2008) 또래유능성 수준을 낮추는 것 으로 보고하고 있다. 이러한 결과는 주 양육자인 어머니의 애 정적 양육행동이 유아로 하여금 가정 밖 대인관계에서 안정감 을 갖게 하고 또래들과 긍정적으로 상호작용하는데 기여함을 보여준다.

이러한 어머니의 애정적 양육행동은 유아의 또래유능성 에 영향을 미치는 대표적인 환경적 요인으로서(J. H. Lee \& Moon, 2008) 또래유능성에 직접적인 영향을 미치기도 하지만 유아의 개인적 요인의 매개적 역할을 통해 간접적인 영향을 미치기도 한다. 관련 선행연구에서 어머니의 양육행동과 또 래유능성간의 관계를 매개하는 변인으로 밝혀진 유아 개인적 요인은 유아의 내적표상(Chung \& Lee, 2006)과 정서조절능력 (J. H. Lee \& Moon, 2008) 등이다. Chung과 Lee (2006)는 애착 이론에 근거하여 어머니의 온정적이고 민감한 양육행동이 어 머니에 대한 유아의 안정적이고 긍정적인 표상을 통해 유아 의 또래유능성에 영향을 미침을 확인하였고 J. H. Lee와 Moon
(2008)은 애정적이고 합리적인 어머니의 양육행동이 유아의 정서조절 능력을 통해 유아의 또래유능성에 영향을 미친다고 보고하였다. 이들 연구는 어머니의 양육행동이 유아의 개인적 특성을 통해 또래유능성에 영향을 미침을 확인해주고 있다. 하지만 이들 연구를 제외한 또래유능성에 대한 다수의 선행연 구들은 어머니의 양육행동을 포함하는 환경적 요인(J. H. Lee $\&$ Moon, 2008), 유아의 기질(H.-N. Kim \& Lee, 2008; J. H. Lee $\&$ Moon, 2008), 언어능력(Choi, 2014), 유아의 정서표현력(J.K. Lee \& Moon, 2011), 그리고 정서조절(Choi, 2014; B. Y. Kim, 2015; H.-N. Kim \& Lee, 2008; J. H. Lee \& Moon, 2008; Y. Lim, 2002) 각각의 요인들이 유아의 또래유능성에 미치는 개별적 혹은 상대적 영향력을 확인하고 있을 뿐 어머니의 양육행동과 같은 환경적 요인이 유아의 또래유능성에 미치는 영향에서 유 아개인적 요인의 매개적 역할을 경험적으로 검증한 연구는 비 교적 찾아보기 힘들다.

Morris, Silk, Steinberg, Myers와 Robinson (2007)은 부모의 양 육행동과 가족의 정서적 분위기와 같은 가족환경적 변인이 유 아의 적응에 미치는 영향에서 유아의 정서조절 능력의 매개적 역할을 설명한 삼중구조모델(tripartie model)을 제안한 바가 있다. 이 모델에 따르면 부모와의 애착, 양육행동, 정서적 코칭 등의 부모특성이 유아의 사회적 유능성 및 행동문제를 포함하 는 유아의 적응능력에 직접적인 영향을 미치는 동시에 유아의 정서조절능력을 통해 간접적인 영향을 미친다. 이와 같은 맥 락에서 보면 유아의 또래유능성 또한 부모의 양육행동을 포함 한 환경적 요인의 직접적인 영향을 받는 동시에 유아 개인적 요인을 통해 간접적인 영향을 받을 것으로 예측된다. 따라서 본 연구에서는 어머니의 애정적 양육행동이 유아의 또래유능 성에 미치는 영향에서 유아 개인적 요인의 매개적 역할을 확 인하고자 한다.

우선 유아의 또래유능성에 영향을 미치는 유아 개인적 요 인 중 정서조절능력은 다수의 연구(Choi, 2014; B. Y. Kim, 2015; H.-N. Kim \& Lee, 2008; J. H. Lee \& Moon, 2008; Y. Lim, $2002 ; \mathrm{Noh}, 2014)$ 에서 그 관련성이 확인되어 왔다. 정서조절능 력이란 정서적으로 자극이 되는 상황에서 사회적인 맥락에 맞 게 반응하고, 적응적이고 유연하게 대응하는 능력으로(Cole, Martin, \& Dennis, 2004), 숙련된 정서조절능력을 보이는 유 아는 다양한 상황에 유연하게 대처하고(Cho, 2015) 협동적이 며 대인관계가 원활하다(Causey \& Dubow, 1992). 반면, 정서 조절능력이 부족한 유아는 또래관계에서 고립된 행동을 보이 거나 어려움을 경험하게 된다(Ji \& Chung, 2011; Kupersmidt \& Dodge, 2004). 이러한 유아의 정서조절은 어머니의 양육행 
동의 영향을 받는데, 어머니가 유아 자녀에게 애정을 많이 표 현하고 지지적일수록 유아는 정서조절 수준이 더 높다(Chae, 2010; Davidov \& Grusec, 2006; H. R. Lee \& Choi, 2005). 이는 어머니의 애정적이고 합리적인 양육행동을 통해 자녀와 긍정 적인 관계를 형성하게 될 때 유아는 긍정적인 정서를 더욱 많 이 경험하게 되고 타인의 정서를 인식하고 조절하는 능력을 더 잘 습득하기 때문으로 추정된다(H.-Y. Lee \& Jang, 2015). 그 러나 어머니가 유아에게 기대와 존중을 표현하지 않고 비지지 적인 반응을 보일수록 유아는 정서조절에 어려움을 겪게 된다 (Jin, 2012). 이와 같이 어머니의 애정적인 양육행동은 유아의 정서조절과 또래유능성에 영향을 미치며, 유아의 정서조절은 유아의 또래유능성에 영향을 미치므로 어머니의 애정적 양육 행동이 유아의 또래유능성에 영향을 미치는 과정에서 유아의 정서조절의 매개적 역할을 추정할 수 있다.

한편 유아의 또래유능성에 영향을 미치는 유아 개인적 요 인 중 유아의 실행기능을 고려할 필요가 있다. 유아기는 종합 적인 사고와 판단을 돕는 전두엽의 급격한 발달이 이루어지 는 시기로, 실행기능 발달의 결정적 시기라고 할 수 있다(B. Y.

Kim, 2015; J. Kim, 2013; Kong, 2012). 실행기능은 상황에 대한 정보를 통합하고 목적에 맞게 주의를 전환하여 그에 맞는 행 동을 수립하는 인지적 과정을 의미한다. 이러한 인지적 과정 은 유아 자신의 사고와 행동을 조절하여 또래와의 갈등을 유 발하는 부정적인 행동을 줄이고 친사회적인 행동을 향상시키 는 데 도움을 준다(Akhgar et al., 2014; K. Y. Kim \& Lee, 2007; Kong, 2012; Nidia, Lynne, Heidi, \& Irene, 2014). 반면, 실행기 능이 낮은 유아는 충동적인 사고와 행동을 통제하는 데에 어 려움이 있다(Anderson, 2002). 따라서 또래유능성 발달을 위해 서는 또래관계에서 상황에 대한 적절한 이해와 행동을 돕는 실행기능의 발달이 선행되어야 함을 알 수 있다.

한편 유아의 실행기능 또한 유아의 정서조절과 마찬가지로 어머니의 애정적 양육행동의 영향을 받는 것으로 보고되고 있 다. 전두엽의 발달과 밀접한 관련이 있는 실행기능은 적절한 환경 제공과 초기 양육자와의 민감한 상호작용이 중요한 영 향을 미친다(Glaser, 2000; Hwang \& Song, 2013). 특히 어머니 의 애정적인 양육행동은 유아에게 동기를 부여해 스스로 행동 을 억제하고 실행기능을 사용할 기회를 증가시킨다(Y.-J. Lee, Kong, \& Lim, 2014). 반면, 어머니의 지나친 간섭과 통제적인 양육행동은 유아에게 스트레스를 유발하여 이는 다시 전두엽 발달에 영향을 미쳐 실행기능 발달에 부정적인 영향을 미친 다(Cha, 2015). 이와 같이 어머니의 애정적 양육행동은 유아의 실행기능과 또래유능성에 영향을 미치며, 유아의 실행기능은
또래유능성에 영향을 미침을 확인할 수 있다. 이러한 관련성 으로 인해 어머니의 애정적 양육행동이 유아의 또래유능성에 영향을 미침에 있어 유아의 실행기능이 매개역할을 할 것으로 추정할 수 있다.

또한 최근 들어 몇몇 연구자들(J. Kim, 2013; J. E. Kim, 2012 ; Song, 2014)은 유아의 정서조절에 영향을 미치는 유아의 실 행기능에 주목하고 있다. 실행기능은 유아가 외부의 자극이나 상황에 맞게 적절하게 자신의 정서를 조절하는데 있어 중요 한 역할을 한다. 즉 우세한 반응을 억제하고 새로운 반응을 활 성화시키는 실행기능은 유아가 목적에 맞게 반응을 통제하고 대책을 세우도록 함으로써(J. Kim, 2013; J. E. Kim, 2012), 분 노와 슬픔과 같은 부정적인 정서를 조절하게 하게 한다(Song, 2014). 따라서 유아의 실행기능은 유아의 정서조절에 유의한 영향을 미침을 알 수 있다.

종합해보면, 어머니의 애정적 양육행동이 유아의 또래유능 성에 영향을 미치는데 있어 유아 개인적 변인인 정서조절과 실행기능이 매개적 역할을 함을 추정해 볼 수 있다. 즉 어머니 의 온정적이고 지지적인 애정적 양육행동은 유아로 하여금 원 활한 또래관계를 형성하고 유지하도록 돕는데 직접적인 기여 를 할 뿐만 아니라, 어머니의 애정적인 양육행동은 유아의 실 행기능을 발달시킴으로써 혹은 유아의 정서조절능력을 향상 시킴으로써 간접적으로 유아의 또래유능성에 영향을 미칠 것 으로 예상된다. 또한 유아의 실행기능은 유아가 상황에 맞게 자신의 정서를 조절하도록 함으로써 또래유능성에 영향을 미 칠 것으로 예상된다.

지금까지 유아의 또래유능성에 관한 연구가 다수 진행되 어 왔으나, 어머니의 양육행동을 포함한 환경적 변인과 개인 적 변인들의 개별적 영향력과 혹은 이들 변인들 간의 상대적 영향력을 확인한 연구들이 다수이며, 환경적 요인이 유아 개 인적 요인의 매개적 역할을 통해 또래유능성에 미치는 영향 을 확인한 연구(Chung \& Lee, 2006; J. H. Lee \& Moon, 2008) 는 매우 제한적이다. 특히 B. Y. Kim (2015)은 유아의 또래유능 성을 인지와 정서 영역의 상호교류를 통한 결과물로 보는 발 달의 총체적 관점에서 다루어야 함을 강조한 바 있다. 따라서 본 연구에서는 최근 주목받고 있는 유아의 인지적 능력인 실 행기능과 정서적 요인인 유아의 정서조절의 매개적 역할을 함 께 살펴보고자 한다. 이를 통해 어머니의 애정적 양육행동이 유아의 또래유능성 발달에 미치는 영향에 있어 유아의 개인적 특성 특히 인지적 특성과 정서적 특성의 매개적 역할을 확인 함으로써 유아기 또래유능성에 대한 이해를 높이고 효과적인 지도를 위한 실증적 자료를 제공하고자 한다. 
따라서 본 연구에서는 선행연구에 근거하여 다음과 같이 연구문제를 제시하고 가설적 연구모형을 설정하여 아래의 Figure 1에 제시하였다.

\section{연구문제 1}

어머니의 애정적 양육행동, 유아의 실행기능, 정서조절 그리 고 또래유능성의 관계는 어떠한가?

\section{연구문제 2}

유아의 실행기능과 정서조절은 어머니의 애정적 양육행동이 또래유능성에 미치는 영향을 매개하는가?

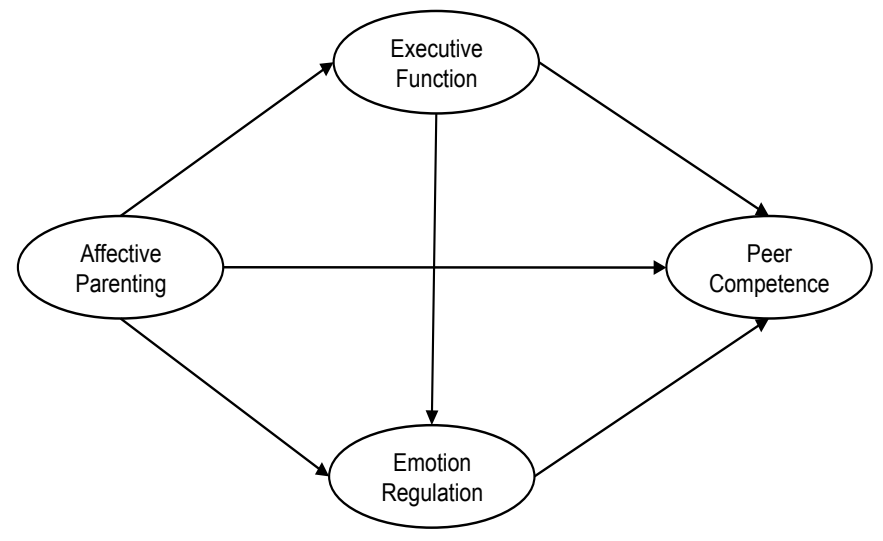

Figure 1. Hypothesized model.

\section{연구방법}

\section{연구대상}

본 연구의 대상은 만 $3,4,5$ 세 남녀 유아 총 241 명(남아 125 명, 여아 116 명)과 그들의 어머니이다. 연구대상자의 일반 적 특성을 보면, 유아의 연령은 만 3세 80명(33.2\%), 만 4세 79명(32.8\%), 만 5세 82명(34.0\%)이었고, 성별은 남아 125 명 $(51.9 \%)$, 여아 116 명(481\%)이었다. 유아의 출생순위는 외 동 47명(19.5\%), 첫째 73명(30.3\%), 둘째 101명(41.9\%), 셋째 이하 20 명 $(8.3 \%)$ 이었다. 어머니의 연령은 35-39세가 123 명 (51.0\%)으로 가장 많았고, 어머니의 학력은 대학교 졸업이 99 명(41.1\%)으로 가장 많았다. 어머니의 직업은 전업주부가 82 명(34.0\%)으로 가장 많았고, 그 뒤로 사무직 58명(24.1\%), 전 문직 36명(14.9\%) 등이 있었다. 가정 월평균소득은 300-399만 원 이하가 72 명(29.9\%)으로 가장 많았다.

\section{연구도구}

\section{유아의 또래유능성}

유아의 또래유능성을 평정하기 위해 Park과 Rhee (2001)가 개 발한 또래유능성 척도를 사용하였다. 총 15 문항으로 사교성, 친사회성, 주도성 3 가지 하위요인으로 구성되어 있다. 사교성 은 또래 집단에 잘 수용되어 두루 어울릴 수 있는 능력을 의미 하며, 친사회성은 다른 아동과 사이좋게 지내고 갈등을 적절히 해결하는 능력을 측정한다. 주도성은 또래집단에서 자신의 의 견을 효과적이고 능동적으로 주장하는 능력을 나타낸다. 유아 의 담임교사가 평정하였으며, 5 점 척도로 전혀 그렇지 않다 1 점부터 매우 그렇다 5점까지이며, 점수가 높을수록 또래유능 성 수준이 높은 것을 의미한다. 본 도구의 Cronbach's $\alpha$ 계수는 전체 .97 , 사교성 .95 , 친사회성 .91 , 주도성 .93으로 나타났다.

\section{어머니의 애정적 양육행동}

어머니의 애정적 양육행동을 평정하기 위해 Schaefer (1959) 가 개발한 어머니의 양육태도 척도(Maternal Behavior Research Instrument [MBRI])를 W. Y. Lee (1983)이 번안하고, Kong (2012)이 수정한 척도를 수정하여 사용하였다. Kong (2012) 의 척도 중 애정적 양육행동을 나타내는 문항을 선택하여 총 22 문항으로 재구성하였다. 유아의 어머니가 평정하였으며, 5 점 척도로 전혀 그렇지 않다 1점부터 매우 그렇다 5점까지이 며, 점수가 높을수록 어머니의 애정적 양육행동을 의미한다. Cronbach's $\alpha$ 계수는 .85로 나타났다.

\section{유아의 실행기능}

유아의 실행기능을 평정하기 위해 Gioia, Isquith, Guy와 Kenworth (2000)가 개발한 유아용 행동 평정 척도 (Behavior Rating Inventory of Executive Function-Preschool version [BRIEF-P]) 를 Seo (2011)가 번안한 척도를 사용하였다. BRIEF-P는 유아 의 일상생활에서 관찰되는 실행기능을 부모 혹은 교사가 평가 할 수 있도록 개발된 것으로(Isquith, Gioia, \& Espy, 2004) 평가 자(부모 혹은 교사) 대상으로 사전 교육이나 훈련 없이 적용할 수 있도록 개발되었다. 실행기능의 장애를 예측하는데 성공적 인 척도임이 밝혀진 바 있으며(Di Pinto, 2006), 최근에는 국외 의 다른 문화권에서도 척도의 타당성이 확보되었다(Bonillo, Araujo Jimenez, Jane Ballabriga, Capdevila, \& Riera 2012; Duku 
\& Vaillancourt, 2014). 본 연구에서는 유아의 담임교사가 평정 하였으며 정확성을 높이기 위해 교사들로부터 문항 이해도를 확인하고 평정 기간을 한 달 가량 제공하였다. 본 연구에서는 억제, 주의전환, 작업기억, 계획조직의 4 가지 하위요인을 사 용하여 총 53 문항이며, 억제는 충동적으로 행동하지 않고 제 어할 수 있는 능력을, 주의전환은 상황에 유연하게 대처하는 능력을, 작업기억은 과제 수행에 필요한 정보를 수용하는 용 량을, 계획조직은 목표를 설정하고 적절한 계획을 세우는 능 력을 평정한다. 4점 척도로 전혀 그렇지 않다 1점부터 매우 그 렇다 4점까지이며, 점수가 높을수록 실행기능 수준이 높은 것 을 의미한다. Cronbach's $\alpha$ 계수는 전체 .98, 억제 .97, 주의전환 .90 , 작업기억 .97 , 계획조직 .94로 나타났다.

\section{유아의 정서조절}

유아의 정서조절을 측정하기 위해 Shields와 Cicchetti (1997)가 개발한 정서조절척도(Emotion Regulation Checklist [ERC])를 J. Kim (2013)이 번안하고 수정한 척도를 사용하였다. 불안정/ 부정성(lability/negativity)과 정서조절(emotion regulation) 중 정 서조절에 해당하는 문항을 추출하여 총 9문항으로 구성하였 다. 유아의 담임교사가 평정하였으며, 4 점 척도로 전혀 그렇지 않다 1점부터 매우 그렇다 4점까지이며, 점수가 높을수록 유 아가 자신의 정서를 잘 조절하여 사회적으로 적절한 방식으로 정서를 표현하는 것을 의미한다. Cronbach's $\alpha$ 계수는 .83으로 나타났다.

\section{연구절차}

부산, 경남 지역에 위치한 3 개의 어린이집 총 17 개 학급을 방 문하여 2016년 7월 11일부터 8월 22일까지 조사를 실시하였 다. 어린이집에 방문하여 질문지를 전달하고, 작성이 완료된 후 직접 방문하여 회수하였다. 어머니의 애정적 양육행동에 대한 질문지는 유아편으로 가정에 배부한 후 회수하였고, 유 아의 실행기능, 정서조절, 또래유능성에 대한 질문지는 각 유 아의 담임교사 17 명이 평정하였다. 교사 간 주관적 견해 차이 로 인한 평가 오류를 줄이기 위해 의미전달이 명확하지 않거 나 이해가 곤란한 문항이 있는지 교사들로부터 확인하고 필요 시 추가설명을 하였다. 또한 응답의 집중도와 성실도를 높이 기 위해 평정 기간을 한 달 가량 충분히 제공하였다. 배부된 질 문지는 294 부였으며, 이 중 262부가 회수되어 약 $89 \%$ 의 회수 율을 보였다. 회수된 질문지 중 응답이 누락되었거나 대상이
적절치 않은 자료를 제외하여 총 241 부가 연구에 사용되었다.

\section{자료분석}

수집된 자료는 SPSS 23.0 (IBM Co., Armonk, NY)과 Amos 23.0 (IBM Co., Armonk, NY) 프로그램을 이용하여 분석하였다. 측 정도구의 신뢰도를 확인하기 위하여 Cronbach's $\alpha$ 계수를 산 출하고, 연구 대상의 인구통계학적 특성을 살펴보기 위하여 빈도분석, 기술통계를 실시하였다. 측정 변인들 간의 관계를 알아보기 위해 Pearson 상관관계분석을 실시하고, 어머니의 애 정적 양육행동과 유아의 또래유능성 간의 관계에서 유아의 실 행기능과 정서조절의 매개효과를 검증하기 위해 구조방정식 분석을 실시하였다.

\section{연구결과}

\section{주요 변인들 간의 상관분석}

주요 변인들 간의 상관관계를 파악하기 위해 Pearson 상관계 수를 산출하였다. 그 결과는 Table 1 과 같다. 모의 애정적 양육 행동은 유아의 실행기능 $(r=.15, p<0.5)$, 정서조절 $(r=.10, p<$ $0.5)$, 또래유능성 $(r=.17 p<0.1)$ 과 유의미한 정적상관이 나타 났다. 유아의 실행기능은 정서조절 $(r=.62, p<0.1)$, 또래유능 성 $(r=.56, p<0.1)$ 과 유의미한 정적상관이 나타났으며, 유아 의 정서조절과 또래유능성 간에도 유의미한 정적상관이 나타 났다 $(r=.63, p<0.1)$. 즉, 애정적 양육행동, 실행기능, 정서조 절, 또래유능성 간에는 모두 유의미한 정적 상관이 있는 것으 로 나타났다.

\section{측정모형 검증}

측정모형의 타당성을 검증하기 위해 확인적 요인분석을 실시

\section{Table 1}

Correlations Among Major Variables

\begin{tabular}{lccc}
\hline \multicolumn{1}{c}{ Variable } & $\begin{array}{c}\text { Affective } \\
\text { parenting }\end{array}$ & $\begin{array}{c}\text { Executive } \\
\text { function }\end{array}$ & $\begin{array}{c}\text { Emotion } \\
\text { regulation }\end{array}$ \\
\hline Affective parenting & - & & \\
Executive function & $.15^{*}$ & - & \\
Emotion regulation & $.10^{*}$ & $.62^{* *}$ & - \\
Peer competence & $.17^{* *}$ & $.56^{* *}$ & $.63^{* *}$ \\
\hline
\end{tabular}


Table 2

Model Fit Indices for Measurement Model

\begin{tabular}{cccccccc}
\hline & $\chi^{2}$ & $d f$ & $p$ & TLI & NFI & CFI & RMSEA \\
\hline Measurement model & 167.00 & 59 & .00 & .94 & .94 & .96 & .08 \\
\hline
\end{tabular}

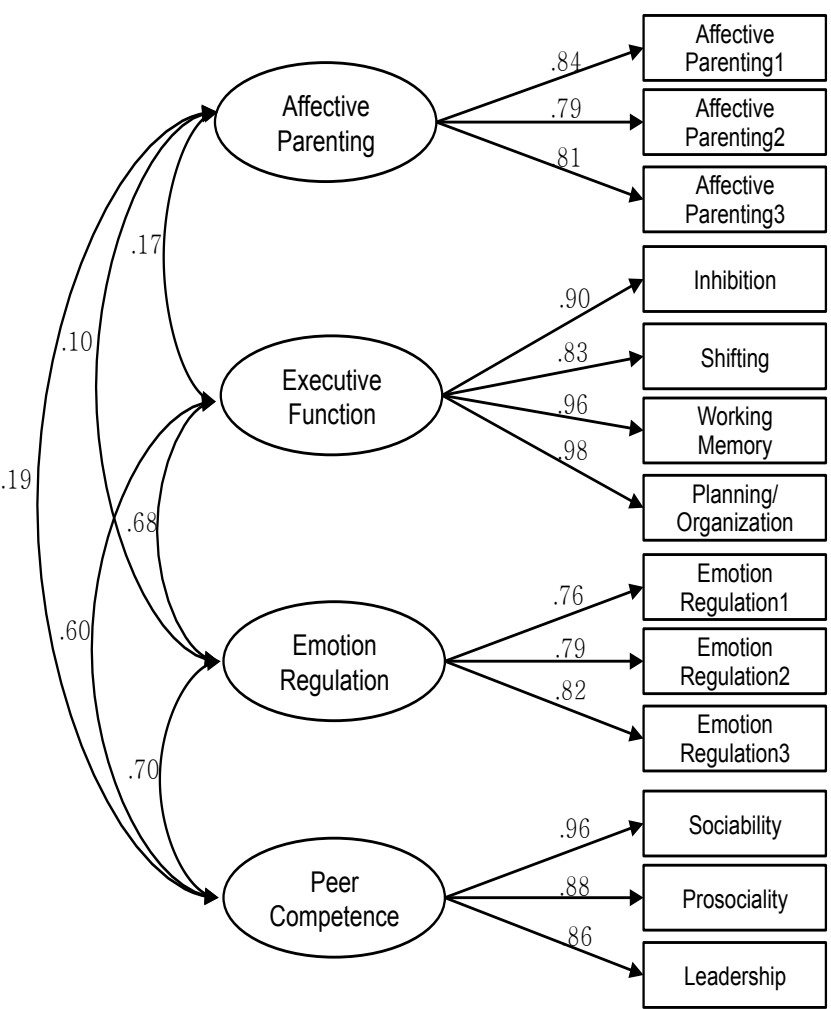

Figure 2. Confirmatory factor analysis of the measurement model.
하였고 측정모형의 적합도는 Table 2 와 같다. $\chi^{2}$ 검증은 표본 크기의 영향을 많이 받으므로 본 연구에서는 TLI, NFI, CFI, $\mathrm{RMSEA}$ 를 함께 고려하여 측정모형의 적합도를 분석하였다. $\chi^{2}$ 값은 $167.00(d f=59, p<.001)$, TLI는 .94, NFI는 .94, CFI는 $.96, \mathrm{RMSEA}$ 는 .08, $90 \% \mathrm{CI}[.07,1.0]$ 로 본 연구의 측정모형은 수용 가능한 모델로 나타났다.

다수의 문항이 한 개의 잠재변인을 구인하고 있는 애정적 양육행동과 정서조절은 문항을 그대로 측정변인으로 사용하 면 구조방적식의 정규분포 위배 가능성이 높아지므로 문항꾸 러미(item parceling)를 통해 3 개의 항목으로 묶어 사용하였다.

요인부하량을 통해 각 측정변인들이 잠재변인을 얼마나 잘 설명해주고 있는지 확인할 수 있는데, 요인부하량의 절대값 이 .50를 넘으면 중요한 측정변인이라고 할 수 있다(K. S. Kim, 2010). 확인적 요인분석 결과, Figure 2 와 같이 전체 요인부하 량이 .76 .96로 .50이상이므로 각 측정변인은 잠재변인을 잘 설명하고 있다고 할 수 있다.

\section{구조모형 검증}

연구모형의 적합도를 살펴보기 위해 TLI, NFI, CFI, RMSEA

Table 3

Model Fit Indices for Research Model

\begin{tabular}{cccccccc}
\hline$\chi^{2}$ & $d f$ & $p$ & TLI & NFI & CFI & RMSEA \\
\hline Research model & 167.00 & 59 & .00 & .95 & .94 & .96 & .08 \\
\hline
\end{tabular}

Table 4

Path Coefficient for Research Model

\begin{tabular}{llllllll}
\hline \multicolumn{2}{c}{ Path from latent to latent variables } & $B$ & $\beta$ & $S E$ & C.R. & $p$ \\
\hline Affective parenting & $\rightarrow$ & Executive function & .32 & .17 & .19 & 2.45 & \\
Affective parenting & $\rightarrow$ & Emotion regulation & -.02 & -.02 & .06 & -0.33 & $n s$ \\
Affective parenting & $\rightarrow$ & Peer competence & .24 & .10 & .13 & 1.86 & $n s$ \\
Executive function & $\rightarrow$ & Emotion regulation & .39 & .68 & .04 & 9.86 & $* *$ \\
Executive function & $\rightarrow$ & Peer competence & .26 & .20 & .10 & 2.62 & $* 2$ \\
Emotion regulation & $\rightarrow$ & Peer competence & 1.27 & .56 & .20 & 6.45 & $* *$ \\
\hline
\end{tabular}

${ }^{*} p<.05 .{ }^{* *} p<.01$ 
Table 5

Comparison of Model Fit Indices

\begin{tabular}{lccccccc}
\hline & $\chi^{2}$ & $d f$ & $p$ & TLI & NFI & CFI & RMSEA \\
\hline Research model & 167.00 & 59 & .00 & .95 & .94 & .96 & .08 \\
Modified model & 170.48 & 61 & .00 & .95 & .94 & .96 & .08 \\
Difference & 3.48 & 2 & & & & \\
\hline
\end{tabular}

Table 6

Path Coefficient for Final Model

\begin{tabular}{llllllll}
\hline \multicolumn{2}{c}{ Path from latent to latent variables } & $B$ & $\beta$ & $S E$ & C.R. & $p$ \\
\hline Affective parenting & $\rightarrow$ & Executive function & .32 & .17 & .13 & 2.47 & $*$ \\
Executive function & $\rightarrow$ & Emotion regulation & .39 & .68 & .04 & 9.95 & $* *$ \\
Executive function & $\rightarrow$ & Peer competence & .29 & .22 & .10 & 2.91 & $* *$ \\
Emotion regulation & $\rightarrow$ & Peer competence & 1.27 & .55 & .20 & 6.38 & $* *$ \\
\hline
\end{tabular}

${ }^{*} p<.05 .{ }^{* *} p<.01$.

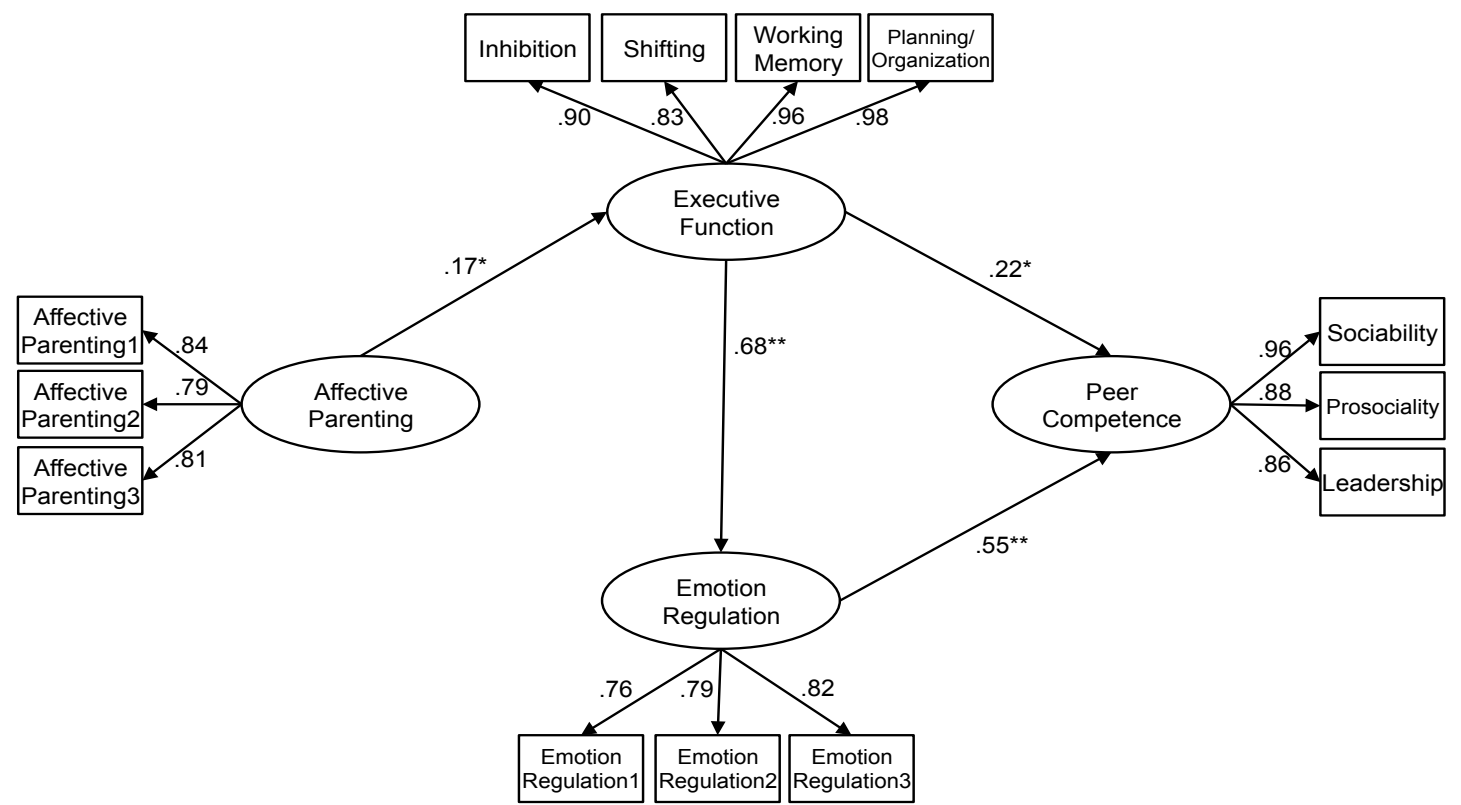

Figure 3. The final model: The mediating influence of preschoolers' executive function and emotion regulation on the relationships between mothers' affective parenting and preschoolers' peer competence.

${ }^{*} p<.05 .{ }^{* *} p<.01$.

지수를 분석하였다. Table 3에 제시된 바와 같이, TLI는 .95, NFI는 .94, CFI는 .96, RMSEA는 .08로 본 연구의 연구모형은 적절한 구조모형의 기준을 충족시켰다.

연구모형에서 각 변인 간 경로계수는 Table 4 와 같다. 연구 모형에서 대부분 유의미한 직접적 경로가 나타났지만, 애정적 양육행동 $\rightarrow$ 정서조절, 애정적 양육행동 $\rightarrow$ 또래유능성은 통
계적으로 유의미한 경로가 나타나지 않았다. 유의하지 않은 경로를 제외하여 수정모형을 설정하였다.

연구모형과 수정모형의 적합도를 비교한 결과는 Table 5 와 같고, 두 모형의 적합도 모두 적절한 구조모형의 기준을 충족 하였다. 두 모형 간 자유도 $(d f)$ 의 차이가 2 인 경우, $\chi^{2}$ 의 임계치 가 5.99보다 작으면 .05 수준에서 통계적으로 유의한 차이가 
Table 7

Direct, Indirect and Total Effects in the SEM

\begin{tabular}{llllcc}
\hline \multicolumn{2}{c}{ Path from latent to latent variables } & Direct effect & Indirect effect & Total effect \\
\hline Affective parenting & $\rightarrow$ & Executive function & $.17^{*}$ & - & $.17^{*}$ \\
Affective parenting & $\rightarrow$ & Emotion regulation & - & $.12^{*}$ & $.12^{*}$ \\
Affective parenting & $\rightarrow$ & Peer competence & - & $.10^{*}$ & $.10^{*}$ \\
Executive function & $\rightarrow$ & Emotion regulation & $.68^{* *}$ & - & $.68^{* *}$ \\
Executive function & $\rightarrow$ & Peer competence & $.22^{*}$ & $.38^{* *}$ & $.60^{* *}$ \\
Emotion regulation & $\rightarrow$ & Peer competence & $.55^{* *}$ & - & $.55^{* *}$ \\
\hline
\end{tabular}

${ }^{*} p<.05 .{ }^{* *} p<.01$.

없기 때문에 간명한 모델을 채택할 수 있으며(Hong, 2013), 모 형을 설정함에 있어 가능한 간명하면서도 높은 적합도를 보이 는 모델이 가장 바람직하다(Bea, 2011). 본 연구의 연구모형과 수정모형 간의 $\chi^{2}$ 의 차이는 3.48 로 두 모형 간 유의한 차이가 없는 것으로 나타났으므로 자유도가 더 크고 간명한 수정모형 을 최종모형으로 채택하였다.

최종모형의 경로계수를 알아보고, 통계적 유의성을 검증하 였다. 그 결과, 각 변인 간 경로계수는 Table 6 과 같다. 모의 애 정적 양육행동에서 유아의 실행기능에 이르는 경로 $(\beta=.17, p$ $<.05)$, 유아의 실행기능에서 정서조절 $(\beta=.68, p<.01)$ 과 또래 유능성 $(\beta=.22, p<.01)$ 에 이르는 경로, 정서조절에서 또래유 능성에 이르는 경로 $(\beta=.55, p<.01)$ 가 모두 유의하게 나타났 다. 최종모형은 Figure 3 과 같다.

주요 변인들 간의 직·간접효과 및 총효과의 통계적 유의성 을 검증하기 위해 부트스트랩핑(bootstrapping)을 실시한 결과 는 Table 7과 같다. 어머니의 애정적 양육행동은 유아의 실행 기능에 직접적인 영향 $(\beta=.17, p<.05)$ 을 미치고, 유아의 정서 조절에는 직접적인 영향을 미치지 않고 실행기능을 통해 간접 적인 영향 $(\beta=.12, p<.05)$ 만 미치며, 유아의 또래유능성에도 간접적인 영향 $(\beta=.10, p<.05)$ 만 미치는 것으로 나타났다. 유 아의 실행기능은 정서조절 $(\beta=.68, p<.01)$ 과 또래유능성 $(\beta=$ $.22, p<.05)$ 에 직접적인 영향을 미치는 동시에 정서조절을 통 해 또래유능성에 간적접인 영향 $(\beta=.38, p<.01)$ 을 미치는 것 으로 확인되었다. 유아의 정서조절은 또래유능성 $(\beta=.55, p<$ .01)에 직접적인 영향을 미치는 것으로 나타났다.

\section{논의 및 결론}

본 연구에서는 어머니의 애정적 양육행동, 유아의 실행기능,
정서조절 그리고 또래유능성의 관계를 알아보고, 어머니의 애 정적 양육행동과 유아의 또래유능성 간의 관계에 있어 유아의 실행기능과 정서조절의 매개효과를 구조모형 분석을 통해 살 펴보았다. 이를 통해 유아의 또래유능성 발달에 대한 이해를 넓히고 효과적인 지도를 위한 실증적 자료를 제공하고자 하였 다. 본 연구의 주요 결과를 요약하고 논의하면 다음과 같다.

첫째, 어머니의 애정적 양육행동, 유아의 실행기능, 정서조 절 그리고 또래유능성 간의 관계를 살펴본 결과 모두 유의미 한 정적 상관관계가 나타났다. 이는 어머니가 애정적으로 양 육행동을 보일수록 유아의 실행기능, 정서조절, 또래유능성 발달 수준이 높게 나타나며, 유아의 실행기능, 정서조절, 또래 유능성 발달 간에도 서로 관련성이 있음을 의미한다. 이러한 결과는 어머니가 애정적인 양육행동을 많이 할수록 유아는 실 행기능 발달 수준이 높고(Glaser, 2000; Y.-J. Lee et al., 2014), 정 서를 상황에 적절히 조절하며(Chae, 2010; H. R. Lee \& Choi, 2005; H.-Y. Lee \& Jang, 2015) 또래유능성 수준이 높다고(Choi, 2014; J. H. Lee \& Moon, 2008; Y. Lim, 2002; Park \& Rhee, 2001) 보고한 선행연구들과 일치한다. 또한 유아의 실행기능 과 정서조절(J. Kim, 2013; J. E. Kim, 2012; Song, 2014), 유아의 정서조절과 또래유능성(Causey \& Dubow, 1992; Y. Lim, 2002; Noh, 2014) 간의 정적 상관관계를 보고한 연구들과 일치하는 결과이다. 그리고 유아의 실행기능과 또래 상호작용(Akhgar et al. 2014; K. Y. Kim \& Lee, 2007; Nidia et al., 2014) 간의 정적 상 관관계를 보고한 선행연구들과 같은 맥락으로 볼 수 있다.

이와 같은 결과를 통해 유아의 실행기능, 정서조절, 또래유 능성 발달은 서로 관련이 있으며 이들은 모두 어머니의 애정 적인 양육행동과 상관이 있음을 확인할 수 있었다. 따라서 유 아의 또래유능성 발달에 있어 또래관계뿐만 아니라 관련된 다 양한 영역의 발달을 함께 증진시킬 필요가 있다.

둘째, 어머니의 애정적인 양육행동이 유아의 실행기능 발 
달을 매개로 유아의 또래유능성 발달에 영향을 미치는 것으로 나타났다. 이는 어머니의 애정적 양육행동이 유아의 또래유 능성에 영향을 미침에 있어 유아의 실행기능을 발달시킴으로 써 이를 통해 또래유능성에 간접적으로 영향을 미친다는 것을 의미한다. 이러한 결과는 어머니의 애정적인 양육행동이 유 아의 실행기능 발달을 촉진시키고(Cha, 2015; Hwang \& Song, 2013), 이러한 실행기능의 발달이 유아의 또래유능성에 영향 을 미친다는(B. Y. Kim, 2015) 선행연구들과 일치한다. 같은 맥 락의 선행연구들을 보면, E. K. Kim (2010)은 어머니의 정서반 응태도가 유아의 또래유능성 발달에 미치는 영향에 있어 유아 의 대인간 문제해결능력이 매개한다고 하였다. 유아의 정서표 현에 대해 어머니가 인정하고 수용적인 태도를 보임으로써 유 아가 대인간문제에 긍정적인 해결방안을 고안하는 능력을 높 여 또래 유능성을 높인다는 것이다. 그리고 어머니의 양육행 동과 같은 환경적 요인이 유아의 인지적인 차원에 영향을 줌 으로써 또래 유능성을 증진시킨다는 Chung과 Lee (2006)의 견 해 또한 본 연구결과를 지지한다. Woo (2014)에 따르면 가정 에서 유아와 반응적으로 상호작용하고 발달을 촉진시키는 환 경을 제공하는 것은 유아가 정보에 대해 이해하고 문제해결방 안을 탐색하는 능력을 증진시켜 또래관계에서 적절한 대처 행 동을 할 수 있게 한다고 한다. 애정적 양육행동 평정 항목을 보 면 자녀에 대한 정서, 애정 표현, 의견 존중 등에 관련된 내용 이다. 어머니가 유아에 대한 긍정적인 표현을 자주하고 유아 의 의견을 수용하고 지지해줌에 따라 유아는 적극적으로 자신 의 목표를 달성하고자 시도하게 되고, 그 과정에서 유아는 필 요한 기술들을 습득할 수 있는 기회를 많이 제공받아 실행기 능을 더욱 발달시키게 되는 것으로 추측할 수 있다. 자극에 대 한 반응을 억제하고 문제에 대한 유연한 태도로 주의를 전환 하는 유아의 인지적 능력은 다양한 사회적 환경에 대한 적절 한 대처와 관련되어 유아는 주변의 상황이나 또래에 대한 관 심과 흥미를 갖게 된다(Akhgar et al., 2014). 따라서 유아가 또 래와 잘 어울리고 적절히 상호작용을 잘 하기 위해서는 유아 의 실행기능을 발달시킬 수 있도록 가정에서 어머니의 애정적 인 양육행동이 이루어져야 함을 시사한다.

셋째, 어머니의 애정적 양육행동과 유아의 또래유능성의 관계에서 유아의 실행기능과 정서조절의 이중매개효과가 나 타났다. 어머니의 애정적 양육행동이 유아의 또래유능성에 직접적으로 영향을 미치는 것이 아니라, 유아가 자신의 목적 에 맞게 반응을 통제하는 능력을 발달시키도록 환경을 제공 하고, 이러한 과정을 거쳐 발달된 유아의 실행기능 능력은 상 황에 적절하게 자신의 정서를 조절하여 표현하는데 영향을 미
침으로써 유아가 또래와의 관계에서 적절한 상호작용을 할 수 있도록 간접적인 영향을 미치는 것이다. 이 네 변인을 함께 살 펴본 선행연구가 부재하므로 유사한 맥락의 연구를 살펴보 면, Morris 등(2007)이 삼중구조모델을 토대로 유아의 사회적 인 적응 능력 발달에 양육행동 등과 같은 부모의 특성이 유아 의 정서조절을 통해 간접적인 영향을 미친다고 보고하였으며, E.-K. Kim과 Song (2007)은 어머니가 유아 자녀의 정서를 인정 하고 애정적으로 반응할수록 자녀로 하여금 정서를 정확하게 인식하고 적절히 표현하게 함으로써 또래와 긍정적인 상호작 용을 가능하게 한다고 하였다. 그리고 B. Y. Kim (2015)은 유아 의 또래유능성 발달에 있어 유아의 실행기능, 자아존중감, 정 서지능의 상대적인 영향력을 살펴보았는데, 자아존중감을 제 외한 실행기능과 정서지능에서만 유의한 영향력이 미침을 확 인하고 유아의 사회적 발달에서 인지, 정서적 발달의 중요성 을 강조하였다. 특히 정서지능은 정서조절을 포함하는 개념으 로 본 연구와 일치하는 점을 확인할 수 있다. 나아가 본 연구에 서는 또래유능성에 대한 영향뿐만 아니라 유아의 실행기능, 정서조절 그리고 또래유능성 간의 통합적인 관계를 확인했다 는 점에서 의미있는 결과라 할 수 있다.

본 연구 결과로 어머니의 애정적 양육행동이 유아의 실행 기능 발달을 돕고, 유아의 유연한 실행기능은 자신의 정서를 상황에 적절하게 조절하여 표현하는데 영향을 미침으로써 유 아가 또래관계에서 유능성이 높아지는 순차적 과정을 확인할 수 있었다. 유연하게 주의를 전환하는 능력이 발달된 유아는 타인의 얼굴 표정이나 상황의 원인 등과 같은 정서적 상황과 관련된 복잡한 요소들을 인지적으로 잘 분류하고 수용하여 정 서에 대한 이해가 높고(Eva, Ana, Manuela, \& Carla, 2016), 목 표에 방해되는 자극을 억제하여 행동을 조절할 수 능력이 발 달됨으로써 충동적인 정서적 반응을 억제하고 적절히 조절하 는 능력이 발달하게 된다(J. E. Kim, 2012). 정서조절 능력이 높 은 유아는 또래와의 관계에서 긍정적인 반응을 많이 보이고, 다른 또래들의 정서에 관심을 갖고 자신의 반응을 적절히 조 절하기 때문에 또래들에게 잘 수용되어 집단 내에서 긍정적인 상호작용이 많이 이뤄지고 관계가 유지될 수 있다. 즉, 또래와 상호작용 시 갈등이나 긴장이 유발되는 상황에서 문제 해결을 위해 관련 정보를 유연하게 활용하고 해결책을 모색하여 자극 에 대한 정서적 반응을 적절히 조절함으로써 긍정적인 상호작 용이 증가하고 원만한 또래관계 형성으로 이어지는 것이다. 그리고 어머니의 애정적인 양육행동이 이러한 유아의 실행기 능과 정서조절을 발달시킴으로써 또래유능성을 증진시키게 된다. 어머니의 애정적인 양육행동이 유아의 정서조절 발달에 
실행기능 발달을 통해 영향을 미치는 것은 유아의 정서조절 과정에서 실행기능의 역할이 크며, 정서조절과 실행기능 간 유사성이 높은 기제가 있음을 시사한다.

그리고 예상과는 달리 어머니의 애정적인 양육행동이 유아 의 또래유능성 발달에 미치는 영향에 있어 직접적인 영향은 나타나지 않았다. Kwon과 Park (2003)의 연구에서도 유아가 또래 관계에 잘 참여하는 데에는 어머니의 양육행동보다는 또 래 상호작용 시 나타나는 유아의 개인적 특성이 더 큰 영향을 미쳤다. 뿐만 아니라 유아 개인적 특성과 양육행동을 동시에 살펴보면 어머니의 양육행동의 영향력은 유의하게 나타나지 않았다. 본 연구 결과와 연결지어보면, 유아의 또래유능성 발 달에 영향을 미침에 있어 어머니의 애정적인 양육행동에 비해 유아의 실행기능과 정서조절의 영향이 매우 높으므로 애정적 양육행동의 영향력이 나타나지 않은 것이다. 만일 어머니의 애정적 양육행동과 유아의 또래유능성 만을 놓고 관계를 확인 했다면 유의미한 영향이 나타났을 것으로 예측된다.

또한 어머니의 애정적인 양육행동이 유아의 정서조절 발달 에 직접적인 영향을 미치지 않는 것으로 나타났는데, 이는 유 아의 정서조절에 대한 어머니의 애정적 양육행동의 직접적인 영향을 보고한 선행연구결과들(Chae, 2010; Davidov \& Grusec, 2006; H. R. Lee \& Choi, 2005; Morris et al., 2007)과는 상반되 는 결과이다. 하지만 어머니의 양육태도와 유아의 정서조절, 사회적 발달 간의 관계를 살펴본 S.-S. Lim, Lee와 Kim (2010) 의 연구, Y. $\operatorname{Lim}$ (2002)의 연구에서는 어머니의 애정적 양육태 도와 유아가 자신의 정서를 조절하는 능력 간에는 서로 직접 적인 관련이 없는 것으로 나타났다. 본 연구에서 어머니의 애 정적 양육행동과 유아의 정서조절 간에 정적상관관계로 보아 서로 관련성이 있음은 확인가능하다. 그러나 어머니의 애정적 양육행동이 유아의 정서조절에 대한 직접적인 영향이 나타나 지 않은 것은 정서조절에 영향을 미침에 있어 더욱 높은 영향 을 주는 요인이 관여하고 있음을 추측해 볼 수 있다. 본 연구결 과 애정적 양육행동과 정서조절 관계에서 유아의 실행기능의 매개역할을 하였는데, 이는 실행기능이 정서조절에 보다 높은 영향력을 미치고 있는 것으로 해석할 수 있다. 그리고 어머니 의 애정적 양육행동과 유아의 정서조절의 정의와 이들을 측정 하는 도구 및 방법에 따른 차이도 생각해 볼 수 있다.

본 연구 결과를 토대로 유아의 또래유능성을 증진시키기 위해서는 유아의 사고와 행동을 조절하는 실행기능 향상에 중 점을 둔 지도 및 개입이 유아의 적절한 정서조절을 통해 효과 적으로 작용할 것으로 사료되며, 특히 실행기능의 급격한 발 달이 이루어지는 유아기에 적절한 개입이 필요하다. Alexandra
와 Marie-Pascale (2015)은 만 4, 5세 유아의 인지적 억제 능력을 강화시키는 훈련의 효과를 검증하여, 외부 자극에 대해 인지 적으로 반응을 억제하는 능력을 향상시킴으로써 유아가 부정 적인 감정을 표출하거나 충동적인 행동이 감소하는 것을 확인 하고 연령이 어릴수록 그 효과가 더욱 크게 나타남을 밝혔다.

연구 결과들을 토대로, 본 연구의 의의는 다음과 같다. 첫 째, 현대사회에 유아의 사회성 발달의 중요성이 높아짐에 따 라, 부모의 양육 특성이 유아의 사회적 발달에 미치는 영향에 서 정서조절의 역할을 밝히는 연구는 꾸준히 진행되어왔다. 그러나 본 연구에서는 어머니의 애정적 양육행동과 유아의 또 래유능성 간 관계를 유아의 정서조절뿐만 아니라 실행기능을 통해 인지적 발달과 함께 통합적으로 살펴봄으로써 유아의 또 래유능성 발달에 대한 이해의 폭을 넓히고 효과적인 지도를 위한 실증적 자료를 제공할 수 있었다.

둘째, 유아의 또래유능성을 발달시키기 위해 실행기능과 정서조절 능력 향상이 요구됨과 동시에 이러한 유아의 발달은 어머니의 애정적인 양육행동을 통해 증진됨을 확인할 수 있었 다. 이를 통해 부모교육 현장 및 가정환경에서 유아의 또래유 능성 증진을 위한 어머니의 양육행동의 방향성을 제시하였다.

셋째, 어머니의 애정적 양육행동과 유아의 또래유능성 관 계에서 유아의 실행기능과 정서조절의 이중매개역할을 확인 하였다. 이를 통해 또래관계에 어려움이 있는 유아나 또래유 능성을 높이기 위한 지도를 함에 있어 실행기능과 정서조절 능력 향상을 통한 접근의 필요성을 확인할 수 있었다. 문제 상 황에 사고나 행동을 적절히 전환하고 대처방안을 탐색하는 능 력을 증진시킬 수 있는 프로그램을 적용하여 상황에 적절한 정서조절 능력을 향상시킴으로써 유능한 또래관계에 도움을 줄수 있다.

본 연구의 제한점 및 추후연구를 위한 제언은 다음과 같다. 첫째, 본 연구에서는 어머니의 애정적인 양육행동이 유아의 실행기능, 정서조절, 또래유능성과 유의한 관계가 있는 것으 로 나타났으나, 나머지 주요 변인들 간의 관계에 비해 상대적 으로 관련성이 높지 않게 나타났다. 이는 유아의 이러한 발달 에 미치는 환경적 영향에 있어 어머니의 애정적 양육행동에서 더 나아가 어머니의 정서반응태도, 또래관리전략 등과 같은 보다 구체적인 특성이 높은 영향을 미칠 것으로 추론해 볼 수 있다. 추후 연구에서는 보다 더 구체적인 어머니 양육 관련 변 인을 탐색하여 유아 발달과의 좀 더 긴밀한 관계를 파악할 필 요가 있다.

둘째, 측정 방법에 있어서 양육행동을 제외한 나머지 유아 의 발달 관련 변인들은 모두 보육교사에 의해 측정되어 변인 
간 높은 상관에 기여했을 가능성을 생각해 볼 수 있다. 그리고 측정에 참여한 17 학급의 17 명의 보육교사 간의 개인 간 차이 와 주관적인 판단이 반영되었을 수 있으므로 훈련된 전문가에 의한 관찰이나 과제 등 다양하고 객관적인 접근을 활용하여 측정할 필요가 있다.

셋째, 본 연구에서는 주양육자로써 어머니의 양육 특성과의 관계만 살펴보았는데 점차 아버지들의 양육 참여가 증가하고 가정 안팎으로 그 영향이 증가하고 있는 요즘 아버지의 양육 특 성을 함께 다룸으로써 가정 내에서 유아의 발달에 미치는 영향 을 더욱 폭넓게 살펴보고 유아의 원활한 또래관계를 위한 가정 에서의 효과적인 지도방안 마련에 도움이 될 것이다.

\section{Notes}

This article is a part of the first author's master's thesis submitted in 2017, and was presented as a poster at the 2016 Annual Fall Conference of the Korean Association of Child Studies.

\section{Conflict of Interest}

No potential conflict of interest relevant to this article was reported.

\section{References}

\section{In English}

Akhgar, G., Eszter, S., Catherine, M. H., Vincent, W. J., Albert, H., Albertine, Albertine, .. . Henning, T. (2014). From positive emotionality to internalizing problems: The role of executive functioning in preschoolers. European Child \& Adolescent Psychiatry, 23(9), 729-741. doi:10.1007/s00787014-0542-y

Alexandra, M. S. V., \& Marie-Pascale, N. (2015). Training executive function in preschoolers reduce externalizing behaviors. Trends in Neuroscience and Education, 4(1-2), 3747. doi:10.1016/j.tine.2015.02.001

Anderson, P. (2002). Assessment and development of executive function during childhood. Child Neuropsychology, 8(2), 71-82. doi:10.1076/chin.8.2.71.8724

Bonillo, A., Araujo Jimenez, E. A., Jane Ballabriga, M. C.,
Capdevila, C., \& Riera, R. (2012). Validation of Catalan version of BRIEF-P. Child Neuropsychology, 18(4), 347-355. doi:10.1080/09297049.2011.613808

Causey, D. L., \& Dubow, E. F. (1992). Development of a selfreport coping measure for elementary school children. Journal of Clinical Child Psychology, 21(1), 47-59. doi:10.1207/s15374424jccp2101_8

Cole, P. M., Martin, S. E., \& Dennis, T. A. (2004). Emotion regulation as a scientific construct: Methodological challenges and directions for child development research. Child Development, 75(2), 317-333. doi:10.1111/j.1467-8624.2004.00673.x

Davidov, M., \& Grusec, J. E. (2006). Untangling the links of parental responsiveness to distress and warmth to child outcomes. Child Development, 77(1), 44-58. doi:10.1111/ j.1467-8624.2006.00855.x

Di Pinto, M. (2006). The ecological validity of the Behavior Rating Inventory of Executive Function (BRIEF) in attention deficit hyperactivity disorder: Predicting academic achievement and social adaptive behavior in the subtypes of $A D H D$ (Unpublished doctoral dissertation). Drexel University, Philadelphia.

Duku, E., \& Vaillancourt, T. (2014). Validation of the BRIEF-P in a sample of Canadian preschool children. Child Neuropsychology, 20(3), 358-371. doi:10.1080/09297049.2 013.796919

Eva, C. M., Ana, O., Manuela, V., \& Carla, M. (2016). Emotion understanding in preschool children: The role of executive function. International Journal of Behavioral Development, 40(1), 1-10. doi: 10.1177/0165025414556096

Glaser, D. (2000). Child abuse and neglect and the brain: A review. Journal of Child Psychology and Psychiatry, 41(1), 97-116.

Isquith, P. K., Gioia, G. A., \& Espy, K. A. (2004). Executive function in preschool children: Examination through everyday behavior. Developmental Neuropsychology, 26(1), 403-422. doi:10.1207/s15326942dn2601_3

Kupersmidt, J. B., \& Dodge, K. A. (2004). Children's peer relations: From development to intervention. Washington: American Psychological Association.

Morris, A. S., Silk, J. S., Steinberg, L., Myers, S. S., \& Robinson, L. R. (2007). The role of the family context in the development of emotion regulation. Social Development, 16(2), 361-388. doi:10.1111/j.1467-9507.2007.00389.x

Nidia, A., Lynne, C. H., Heidi, M. F., \& Irene, M. L. (2014). Executive function is associated with social competence in preschool-aged children born preterm or full term. Early Human Development, 90(6), 299-306. doi:10.1016/ j.earlhumdev.2014.02.011

Rohner, R. P., Khaleque, A., \& Cournoyer, D. E. (2005). Parental acceptance-rejection: Theory, methods, cross-cultural evidence, and implications. Ethos, 33(3), 299-334. doi:10.1525/ 
eth.2005.33.3.299

Rubin, K. H., Bukowski, W., \& Parker, J. (2006). Peer interactions, relationships, and groups. In W. Damon, R. M. Lerner, \& N. Eisenberg (Eds.), Handbook of child psychology: Social emotional and personality development (6th ed., Vol. 3), New York: John Wiley \& Sons.

Shaffer, D. R. (2005). Social and personality development (5th ed.). Belmont, CA: Wadsworth/ThomsonLearning.

\section{In Korean}

Bae, B. R. (2011). Structural equation modeling with AMOS 19. Seoul: Cheong-ram.

Cha, K. (2015). Maternal interaction behaviors and the development of executive functions among Korean preschoolers. Korean Journal of Early Childhood Education, 35(2), 117-141. Retrieved from http://www.riss.kr/link?id=A101005526

Chae, Y.-M. (2010). Young children's emotion control \& social ability according to parenting attitude. Journal of Young Child Studies, 13, 117-132. Retrieved from http://www.riss. $\mathrm{kr} / \mathrm{link}$ ?id=A82533925

Cho, S.-H. (2015). The effect of young children's emotion regulation and leadership on preschool adjustment. Early Childhood Education Research \& Review, 19(5), 171-191. Retrieved from http://www.riss.kr/link?id=A101329130

Choi, I. (2014). The effects of preschool children's language ability, emotion regulation, and mothers' parenting behavior on peer competence and aggressive behavior. Journal of Korean Home Management Association, 32(6), 47-58. Retrieved from http://www.riss.kr/link?id=A100328981

Chung, J.-N., \& Lee, Y. (2006). Maternal parenting behaviors and preschoolers' peer competence: Mediating effects of preschoolers' internal representations. Korean Journal of Child Studies, 27(4), 65-80. Retrieved from http://www.riss.kr/ link?id=A102954139

Hong, S. H. (2013). Various models of structural equation model (Unpublished Manuscript). Proceedings of S\&N Research Group, Research Methods Workshop.

Hwang, H.-R., \& Song, H.-J. (2013). Child executive function and parenting. Journal of Rehabilitation Psychology, 20(2), 149-167. Retrieved from http://www.riss.kr/ link?id=A99834646

Ji, M. K., \& Chung, K. S. (2011). A study on the relationship of children's emotional regulation, child-teacher relationship with peer competence. Journal of Life-span Studies, 1(1), 3346. Retrieved from http://www.riss.kr/link?id=A95953679

Jin, Q. (2012). A structural model analysis of relationships among parents' emotion-related socialization behaviors, children's emotion regulation and resilience on children's preschool adjustment (Master's thesis). Retrieved from http://www.
riss.kr/link?id=T12892343

Jung, D.-H., \& Chi, S.-A. (2006). A study of the relationships among children's peer interactions, child-teacher relationships, multiple intelligences, and elementary school adjustment. Korean Journal of Early Childhood Education, 26(3), 201-221. Retrieved from http://www.riss.kr/ link?id=A99534846

Kim, B. Y. (2015). Effect of children's executive function, selfesteem and emotional intelligence on peer competence (Doctoral dissertation). Retrieved from http://www.riss.kr/ link?id=T13819240

Kim, E. K. (2010). The effects of mother's attitude toward children's emotional expressness on preschoolers' peer competence: Preschoolers' emotional ability and interpersonal problem solving strategies as mediating variables. Journal of Future Early Childhood Education, 17(2), 155-181. Retrieved from http://www.riss.kr/link?id=A82535043

Kim, E.-K., \& Song, Y. H. (2007). A study on the relation between mothers' childhood experiences, mother's attitude toward children's emotional expressiveness and preschoolers' emotional ability to preschoolers' peer competence. The Journal of Play Therapy, 11(2), 1-15. Retrieved from http://www.riss.kr/ link?id=A75048246

Kim, H.-N., \& Lee, K.-N. (2008). Young children's temperament, and emotional regulation, mother's parenting behavior and young children's peer competence by children's sex. The Journal of Korea Open Association for Early Childhood Education, 13(5), 71-92. Retrieved from http://www.riss. $\mathrm{kr} /$ link?id=A99891437

Kim, J. (2013). Preschoolers' emotion regulation in different situation: related to executive function and temperament (Doctoral dissertation). Retrieved from http://www.riss.kr/ link?id=T13143372

Kim, J. E. (2012). The effects of executive function of young children on competence of emotion regulation: With its focus on inhibitory, working memory and shifting (Master's thesis). Retrieved from http://www.riss.kr/link?id=T12677656

Kim, K. S. (2010). Structural equation model analysis with Amos 18. Seoul: Hannarae.

Kim, K. Y., \& Lee, S. E. (2007). Young children's executive function and peer interaction according to language abilities. Journal of Future Early Childhood Education, 14(1), 167-197. Retrieved from http://www.riss.kr/link?id=A75129561

Kong, Y. S. (2012). The effect of preschooler's temperament and maternal parenting attitude on preschooler's problem and prosocial behavior: Focusing on the mediating effect of executive function (Doctoral dissertation). Retrieved from http://www.riss.kr/ link?id=T12699288

Kwon, Y. H., \& Park, K. J. (2003). Effects of emotionality, interpersonal problem solving strategies, and maternal 
behaviors on children's social competence. Korean Journal of Child Studies, 24(3), 27-44. Retrieved from http://www. riss.kr/link?id=A102953866

Lee, H. R., \& Choi, B.-G. (2005). The relation between preschoolers' individual and parents' characteristics and preschoolers' emotional understanding and regulation. Family and Environment Research, 43(5), 1-14. Retrieved from http:// www.riss.kr/link?id=A75459398

Lee, H.-Y., \& Jang, K.-E. (2015). The mediating effect of children's emotional regulation on the relationship between mothers' parenting attitude and children's social competence. Early Childhood Education \& Care, 10(1), 5-34. Retrieved from http://www.riss.kr/link?id=A100518206

Lee, J. H., \& Moon, H. J. (2008). Effects of children's emotionality, emotion regulation, and maternal parenting behaviors on children's peer competence. Korean Journal of Child Studies, 29(4), 1-14. Retrieved from http://www.riss. $\mathrm{kr} /$ link?id=A102954172

Lee, J.-K., \& Moon, S.-B. (2011). A structural relationship between the young children's peer competence and its related variables. The Journal of Korea Open Association for Early Childhood Education, 16(6), 249-269. Retrieved from http://www.riss.kr/link?id=A99891800

Lee, Y.-J., Kong, Y.-S., \& Lim, J.-Y. (2014). The effects of parenting behaviors on preschoolers' executive function. Journal of Korean Home Management Association, 32(1), 1326. Retrieved from http://www.riss.kr/link?id=A99925297

Lim, S.-S., Lee, J.-M., \& Kim, Y.-H. (2010). Effects of the mother's parenting \& young children's emotional regulation on sociability. Korean Journal of Family Welfare, 15(2), 143157. Retrieved from http://www.riss.kr/link?id=A82356200

Lim, Y. (2002). Children's peer competence in relation to maternal parenting styles and children's emotion regulation. Family and Environment Research, 40(1), 113-124. Retrieved from http://www.riss.kr/link?id=A75464544

Moon, E.-S. (2007). Relationships between mother's child rearing attitudes and child's adjustment to kindergarten. Korean
Journal of Child Studies, 28(4), 145-154. Retrieved from http://www.riss.kr/link?id=A102953997

Noh, J. H. (2014). The influence of self-efficacy and emotion regulation of young children on peer competence. Journal of Early Childhood Education \& Educare Welfare, 18(3), 185206. Retrieved from http://www.riss.kr/link?id=A100329593

Park, J., \& Rhee, U. (2001). Children's peer competence: Relationships to maternal parenting goals, parenting behaviors, and management strategies. Korean Journal of Child Studies, 22(4), 1-15. Retrieved from http://www.riss. $\mathrm{kr} /$ link?id=A102953635

Seo, J. E. (2011). The effects of executive function of children on emotional intelligence: A comparison between normal children and children with attention problems (Master's thesis). Retrieved from http://www.riss.kr/link?id=T12322340

Song, S. J. (2014). The relationships of cool executive function, hot executive function and emotion regulation of four-year-old boys and girls (Master's thesis). Retrieved from http://www. riss.kr/link?id=T13368062

Woo, D. R. (2014). Mediated effect of 5-year-old children's decisionmaking ability influence of early home environment on peer competence and problematic behavior. Journal of Future Early Childhood Education, 21(1), 139-162. Retrieved from http://www.riss.kr/link?id=A99919882

\section{ORCID}

Ran Hee Yoo http://orcid.org/0000-0002-4614-5534

Sun Hee Kim http://orcid.org/0000-0002-0801-6918

Received December 29, 2016 Revision received March 17, 2017

Accepted April 9, 2017 